\title{
Private Savings and Liquidity Preference: Survey of Zimbabwean Households
}

\author{
Tafadzwa R Chikwanha \\ Department of Economics, University of Fort Hare, Email: chikwanhat@gmail.com \\ Free Ncube \\ Department of Economics, University of Fort Hare, Email: 201013417@ufh.ac.za \\ Jacqueline T Chikwanha \\ Department of Banking and Finance, National University of Science and Technology, \\ Email:jtchikwanha@gmail.com
}

Doi:10.5901/mjss.2014.v5n10p119

\section{Abstract}

Since the 2009 introduction of the multiple currency monetary system and the then formation of a Coalition Government, macroeconomic stability has existed in Zimbabwe. The hyperinflation and perpetually declining real national income were harnessed. The economy has experienced significant growth and remarkably low inflation rates. An unwelcome consequence of the current monetary system in the country has been the inability of the authorities to print money or mint coins and rendering the Reserve Bank of Zimbabwe almost obsolete. With increasing economic activity, business and employment, there has been a general rise in the demand for money. This has outstripped the current money balances in the economy. Liquidity challenges have become the norm in the economy since 2009. Savings are therefore generally low and significantly low compared to regional trends. The primary objective of the study is to record the trends and ascertain the determinants of household savings and the drivers of enhanced liquidity preference in Zimbabwe. The study employed a survey of 315 households in Harare and Bulawayo: the two largest metropolitan cities in Zimbabwe. Using the data gathered, an econometric binary logistic model was estimated. The results showed strong correlation between household savings and bank-specific trends such as the rate of debit and credit card use and demographic factors like the ages of depositors. The study also provided conclusions and both micro and macroeconomic policy recommendations to mitigate the problem.

Keywords: Savings, Liquidity preference, logistic regression

\section{Introduction}

The rate and level of savings in an economy have been postulated by economic theory to be drivers to long term economic growth. Savings are said to provide the loanable funds needed by firms as capital and investment. Furthermore the availability of savings provides a basis for the money creation process subject to the money multiplier and reserve requirements (Mishkin, 2004). The above is universal to all economies. Zimbabwe, since the prolonged economic depression from the turn of the century to around 2008, suffered massive losses in monetary value and in turn the incentive to save. A few years after the economic downturn, the economy is in recovery but still falls short of the targeted growth rates. By end of 2013:Q2, Gross Domestic Product (GDP) growth was 4.96\% achieving US\$8.144 billion against initial projections of $9 \%$ growth (Economy Watch, 2013) ${ }^{1}$. Many factors have been attributed as root causes of the stunted growth among them limited investment (domestic and foreign), inconsistent economic policies, uncertain political landscape and a general lack of confidence in the economy. The latter has had detrimental influences on the operations of many facets of the economy, in particular the financial services sector.

The Reserve Bank of Zimbabwe, RBZ (2012) identified export earnings, remittances from Zimbabwean citizens abroad, foreign direct investment (FDI) inflows, portfolio investment inflows and offshore credit lines (all of which are dependent on confidence in the economy) as sources of liquidity. These generators of liquidity have been and are still largely repressed in Zimbabwe. Additionally, the largely literate population and overzealous media have combined to divulge the weaknesses of the financial sector which has exacerbated uncertainty in risk averse investors. The banking services industry is said to be marred with inadequate capitalization, abuse of corporate structures and widespread violations of banking laws (RBZ, 2012). Within an economy that is largely based on cash transactions, Zimbabwe can be pointed to as being overbanked; with 24 licenced bankers chasing a meager US\$4.4 billion worth of deposits (an increase of 31\% from 2012) (Economist, 2013).

${ }^{1}$ Economy Watch is an online statistical site integrating country-specific statistics and data computed from the CIA, UN, IMF, World Bank and domestic data bases. 
Banking institutions and financial services firms are pivotal agents for economic prosperity. In Zimbabwe confidence in the financial sector, although improving, has not recovered fully from its low points. The effects of the 2004 recuperative curatorship by the central bank of nine banks including CFX Ltd, CFX Merchant, Barbican Bank, Intermarket Building Society, Intermarket Discount House, Royal Bank, Trust Bank Ltd and Trust Bank Corporation still lingers in the economy. Economic Watch (2013), showed Gross National Savings to have been $-25.359 \%, 0.626 \%$ and $4.355 \%$ of GDP in 2011, 2012 and 2013 respectively. Projected national savings were estimated to rise to $7.283 \%$ and $12.407 \%$ in 2014 and 2015 respectively. Economist (2013) pointed out that despite the more that modest growth in national savings, liquidity challenges were still compounded by the short savings period banks were subjected to. Demand deposits last on average 90 days within Zimbabwe's banking institutions thus only short term loans are feasible. 83\% of deposits in Zimbabwean banking institutions are transitory and can be demanded by depositors easily and without prior notice. In October 2012, demand deposits and savings consisted $52.9 \%$ and $11.3 \%$ of deposits respectively (RBZ, 2012). A year later the ratios were respectively $52.7 \%$ and $10.4 \%$ (RBZ, 2013). The former combined with the $100 \%$ loan reserve on unsecured loans required by the Banking Act and the $30 \%$ reserve requirement dampen the credit creation process and weaken the money multiplier (Rukuni, 2013).

It is pivotal that all economic agents including government, firms, households and individuals collude in the ambition to maintain the revival of the economy. Friedman (1956) argued that money and its availability thereof is a key driver of economic growth and development at the macro level. Underpinning these economic suggestions, are the behaviours and attitudes of economic agents at the micro level. The economy and its welfare are therefore sensitive towards the perceptions and actions of the aforementioned economic agents. The typical and pervading problem in the economy currently is the overwhelming liquidity shortage. Money growth in the economy is considered to be generally low and insufficient for vibrant economic growth and development. The status quo is driven by the underwhelming level of savings in Zimbabwe's financial institutions and the high levels of liquidity preference in households. The depleted levels of liquidity in circulation is a joint consequence of the loss of faith in banking institutions (generated by the hyper inflationary conditions that resulted in massive losses of private savings), generally low disposable income levels, exorbitant bank charges vis-à-vis the incomes and the absence of institution-backed incentives towards savings.

The high preference for liquidity has triggered a lackluster financial sector which has in turn resulted in large scale unavailability of loanable funds. Larger and more developed banks in Zimbabwe offer deposit rates of between $0.15 \%$ to $6 \%$, while the emerging institutions offer between $8 \%$ and $16 \%$. This is in light of the lending rates between $5 \%$ and $35 \%$ for individual and corporate loans. These rates joint with the high bank and transaction charges have not helped savings and ultimately at the very least, stunted economic growth (RBZ, 2012).

Furthermore, Econet Wireless, Zimbabwe's largest mobile phone network service provider introduced the EcoCash system. It is a mobile money payment system for subscribers and permits simple financial transactions and money transfer services (Econet, 2013). The service also allows payroll (EcoCash Payroll), bulk and banking services. 2013 saw the introduction of EcoCash Save, a savings account option from the mobile operator which allows deposits and offers deposit interest from balances as minimal as US $\$ 1$. The product is also accompanied by extensive spread of the service through agents even in remote areas were the previously existent financial service providers have been unable to venture. This has provided a massively more attractive option relative to traditional banking. The results has been massive exodus from the orthodox form of banking and conducting transactions to the simpler, more accessible and efficient system provided by Econet.

\section{Brief Overview of Savings in Zimbabwe}

Figure 1: Gross Domestic Savings Trends in Zimbabwe 1980-2012

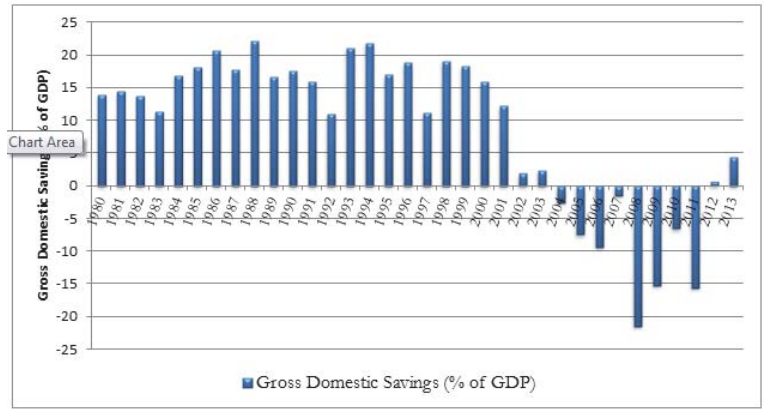

Source: World Bank (2013) 
Figure 1 above shows the Gross Domestic Savings (GDS) trends in Zimbabwe from 1980 to 2012. The GDS are GDP minus final consumption expenditure. They are an indication of the portion of national income that is not consumed or spent. The general trend over the period displays distinctly disaggregated behavior. From 1980 to 2001, GDS were significantly higher compared to the succeeding period to present. Between 1980 and 1983, GDS were generally declining and roving between 10 and 15 percent. This trend could have been a result of the "political uncertainty" that surrounded the political and economic environment in immediate post-independent Zimbabwe. The trend may also have been a consequence of the inherent interventionist strategies adopted by the Government from the colonial regime. The economy comprised strong authoritarian forces that influenced investment, business and profit repatriation (Gwenhamo, 2009). Between 1984 and 1989, the GDS were rising because of the comparatively higher deposit interest rates which were constantly above 10 percent compared to the 3.5 percent during the pre-independence period. Another notable declining trend occurred between 1989 and 1992. With the persistently declining investment levels during the prior period, Government relaxed the amount of profits that foreign firm could repatriate from $50 \%$ to $100 \%$. This was consistent with the requirements of the International Monetary Fund (IMF) proposed Economic Structural Adjustment Programme (ESAP). One of the negative consequences was the decline in the domestic savings. Generally high savings occurred in Zimbabwe until 2002 when unprecedented declines began. By 2002, savings were severely depleted by outflow of labour and capital from Zimbabwe after the implementation of the contentious Land Reform Programme. Savings in the succeeding period were exacerbated by economic turmoil and galloping inflation. Between 2004 and 2011, negative savings occurred due to the hyperinflationary conditions that discouraged saving. The resultant culture of consumption persisted after the 2009 introduction of the multiple-currency monetary system that harnessed inflation. By 2012, improvements began to slowly occur.

\section{Literature Review}

\subsection{Friedman's Quantity theory of Money demand.}

Against the arguments of neutrality of money suggested by Keynes (1936), Friedman reinvented the Quantity theory of money (QTM) as proposed by Irving Fisher (Snowdon and Vane, 2005). The conventional QTM is largely focused on the interaction between the general price level (inflation) and the supply of money. Friedman (1956) argued the QTM as a theory of money demand rather than the latter. The theory postulates that money demand (typical of the demand of any other asset) generates a flow of interest towards the holder and is determined by three main variables. These include (i) wealth- which determines the level of money balances that can be held, (ii) the yield generated from holding the money balances relative to other financial assets and (iii) tastes and preferences of the asset holders- influenced by various socioeconomic dynamics such as gender, race, culture etc (Snowdon and Vane, 2005).

\subsection{Modigliani's Life Cycle Hypothesis}

The Life Cycle Hypothesis (LCH) is a model of savings, the supply of capital and the demand for wealth. The theory derives its implications at both aggregate and household levels (Modigliani, 1963). If tastes and preferences towards resources allocated for consumption are steady over the lifetime of a household, they have the consequence of producing an invariable growth rate in private savings and wealth. This implies that the savings ratio remains constant. The savings ratio also depends on the income growth rate. The underlying concept driving the $\mathrm{LCH}$ is that savings (and thus consumption) decisions formulated by households will always mirror their conscious drive at attaining a preferred distribution of consumption over a life cycle. This is all subject to a resource-imposed constraint on the household and its lifetime. Radical approaches towards the LCH suggest that resources will be completely utilized over the lifecycle of the household i.e. the household has no recorded intent at leaving bequests. The LCH argues that given stable consumption, households will experience negative savings during the initial stages of the lifecycle. At these stages it is assumed households lack the income and wealth to finance sustainable savings. In the intermediate stages of their life cycles, the households save because their income earnings surpass the level of consumption. The ceasation of earnings in the latter stages of the lifecycle causes recurrence negative savings.

The body of empirical literature on savings and liquidity preference is a vast one. Studies have been carried out extensively globally. Typically, though, the size of developing economy-based empirical literature is far less notable. This phenomenon is more pronounced in Africa. The nature, behavior and determinants of savings in low income countries have been studied by Ahmad and Mahmood (2013), Athukorala and Sen (2001), Nwachuku and Egwaikhide (2007) and Cadim de Cavalho (1998). Conversely, in higher income economies, more literature exists. Studies have been carried out 
by Callen and Thimann (2001), Shell, Sidrauski and Stiglitz (1967), Yilmazer (2009), Engen, Gale and Scholz (1996), Loayza, Schmidt-Hebbel and Serven (2000), Kang (2002) and Lung (2002).

\section{Methodology}

\subsection{Data Collection, Processing and Coding}

To acquire the relevant data, a representative portion of the population was selected as a sample. The Simple random sampling technique, which is a Probability sampling method, was utilized. The method was chosen since a level of confidence in the data collection process was needed (MacNealy, 1999). The sample consisted of 315 respondents selected from Zimbabwe's major metropolitans of Harare and Bulawayo. Data were collected via researcher administered interviews. To process the data, the responses were awarded codes on a binary scale and processed via Microsoft Office Excel.

\subsection{Theoretical Framework}

The study utilises Friedman's QTM model specification as the underlying model.

$$
\frac{M_{d}}{P}=f\left(Y^{P} ; r ; P^{e} ; u\right)
$$

where: $Y^{P}=$ permanent income (proxy for wealth/budgetary constraint),

$r=$ return on financial assets,

$P e=$ expected rate of inflation and

$u=$ individuals' tastes and preferences.

The study adopts the 'individuals' tastes and preferences' portion of Friedman's model. The latter is assumed to be a function of various socio-economic determinants which are therein implemented as the regressors of the demand for liquidity. Some variables are adopted from Modigliani's Life-cycle hypothesis. The model is specified below.

$$
L P_{i}=\beta_{k} D_{n}+\varepsilon
$$

where: $L P_{i}=$ Liquidity preference (proxy for demand for liquid balances)

$D_{n}=$ regressor variables including (Income, Age, EcoCash use, Dependents, Cheque, debit and credit card use, access to ATM and location of residence)

$$
\beta=\text { coefficients }
$$

\section{Empirical Model}

The dependent variable in the model LP displays the probability of individuals leaving no savings in banking institutions at any time of the month. This variable follows a Bernoulli distribution and assumes the values of 1 and 0 where there are no savings and where there are savings respectively. To test the conditions, the Binary Logistic model is utilized to maintain the ${ }^{0 \leq E\left(L P_{i} \mid D_{i}\right) \leq 1}$ condition which is inconsistent in the general Linear Probability Model (LPM).

$$
L_{i}=\operatorname{In}\left[\frac{P_{i}}{1-P_{i}}\right]=Z_{i}=\beta_{1}+\beta_{K} D_{n i}+\varepsilon_{i}
$$

$\left[\frac{P_{i}}{1-P_{i}}\right]_{\mathrm{k}}$

shows that $P i$ is the probability of complete liquidity preference while $1-P i$ is the probability of individuals not preferring complete liquidity. $\mathrm{Li}$ represents the logit (Log Odds of liquidity preference against savings). As the logit has no restrictions, it varies from $-\infty$ to $\infty$ while $P i$ is restricted between 0 and 1 because it is non-linear in $D$. To estimate the Odds from the logit, the latter's exponential is implemented in the form:

$$
\left[\frac{P_{i}}{1-P_{i}}\right]=e^{\left(\beta_{1}+\beta_{k} D_{n}+\varepsilon\right)}
$$

Further on, to interpret the probabilities from the odds, the form below is utilized

$$
P_{i}=\frac{e^{\left(\beta_{1}+\beta_{k} D_{n}+\varepsilon\right)}}{1+e^{\left(\beta_{1}+\beta_{K} D_{n}+\varepsilon\right)}}
$$




\section{Findings}

Table 1: Pearson's $\chi^{2}$ Correlations

\begin{tabular}{|c|c|c|c|c|c|c|c|c|c|}
\hline & LP & C1 & C2 & C3 & C4 & C5 & C6 & C7 & C8 \\
\hline \multirow[t]{2}{*}{$\mathrm{LP}$} & 1 & -.003 & $.286^{* k}$ & .032 & -.096 & .006 & $-.389^{* *}$ & $\begin{array}{l}.042 \\
\end{array}$ & $.152^{* *}$ \\
\hline & & .956 & .000 & .572 & .087 & .909 & .000 & .457 & .007 \\
\hline \multicolumn{10}{|c|}{$\mathrm{C}=$ Coefficients in the order: INCOME, ECOCASH, DEPENDENTS_AGE, CARDUSE, ATMACCESS, CONFIDENCE, RESIDENCE AGE } \\
\hline \multicolumn{10}{|c|}{$\begin{array}{l}\text { **. Correlation is significant at the } 0.01 \text { level (2-tailed). } \\
\text { *. Correlation is significant at the } 0.05 \text { level (2-tailed). } \\
\text { a. Listwise } N=315\end{array}$} \\
\hline
\end{tabular}

Table 1 shows the pair-wise correlations estimated using the Pearson's Chi-Square test. The correlations show the direction of movement among the variables. It is important to note that Pearson's test does not show causality among the variables. The test is an important tool in acquiring a primary understanding of the trends and behaviors of the relevant variables in the model. Decisions can be formulated from the results of the Pearson test. Pearson correlations have the disadvantage (especially in the existence of categorical and continuous data variables) of finding statistically significant trends that may be dubious in reality. Regardless, it remains an important starting point for analysis. In the study model, the results show statistically significant (at 5\%) positive correlation between Liquidity Preference and the use of the Eco Cash money transfer system. The results show that individuals who use Eco Cash regularly (which in essence acts as a means of saving, transacting and money transfer), increase LP by 28.6 percent. Another important observation generated by the test is the significantly negative correlation between confidence in the financial services sector and LP. It is clear that an individual who professes confidence in banking is 38.9 percent more likely to save compared to one who has no confidence. The Age variable shows that there is positive correlation between respondents' ages and the preference for liquidity. This result shows the considerable impact of age on the saving behaviors of individuals.

After the Chi-square tests were concluded, the binary-logit regression model was estimated. The results are illustrated in Table 2 below.

Table 2: Binary Logit Findings

\begin{tabular}{|l|c|c|c|c|c|}
\hline \multicolumn{7}{|c|}{ Dethod: ML - Binary Logit (Quadratic hill climbing) } \\
\hline \multicolumn{7}{|c|}{ Variable } & Coefficient/B & Std. Error & Z-Statistic & Prob. & Exp(B) \\
\hline C & 2.288024 & 1.037019 & 2.206348 & 0.0274 & 9.855 \\
\hline INCOME & -0.681683 & 0.507560 & -1.343060 & 0.1793 & 0.505 \\
\hline ECOCASH & 0.327111 & 0.126933 & 2.577032 & 0.0100 & 1.387 \\
\hline DEPENDENTS_AGE & -0.039220 & 0.401751 & -0.097623 & 0.9222 & 0.962 \\
\hline CARDUSE & -1.170377 & 0.441841 & -2.648866 & 0.0081 & 0.310 \\
\hline ATMACCESS & -0.544573 & 0.410488 & -1.326648 & 0.1846 & 0.580 \\
\hline CONFIDENCE & -0.701576 & 0.114001 & -6.154110 & 0.0000 & 0.496 \\
\hline RESIDENCE & -0.869306 & 0.425651 & -2.042297 & 0.0411 & 0.419 \\
\hline AGE & 1.255148 & 0.276626 & 4.537350 & 0.0000 & 0.419 \\
\hline McFadden R-squared & 0.205645 & Obs with Dep=0 & & 187 \\
\hline LR statistic & 87.51577 & \multicolumn{2}{c|}{ Obs with Dep=1 } & & 128 \\
\hline Prob(LR statistic) & 0.000000 & \multicolumn{2}{c|}{ Total obs } & & \\
\hline
\end{tabular}

The coefficient/B shows the logit or log odds of LP. The importance of the log odds coefficients is that they show the direction of relationship between the regressand and regressor variable. Analysis of the model using the log of odds is strenuous and complicated. For ease of analyses, the coefficients are exponentiated to $\operatorname{Exp}(B)$ which are the odds of LP. These show the odds of LP relative to saving subject to each variable ceteris paribus. The null hypotheses are not rejected if the probability is less than the $5 \%$ significance level. This will be supported by a test statistic with an absolute value greater than 2. The model results show ${ }^{2}$ that relatively high income individuals earning (above US $\$ 500$ monthly) are 0.51 times as less likely to prefer absolute liquidity (the results are not statistically significant). The results also show that as an individual moves to a higher age bracket, they are 0.42 times more likely to prefer liquidity. The initial results are consistent with the LCH while the succeeding results are inconsistent. The results also show statistically significant outcomes in terms of the ECOCASH variable. These results imply that individuals who use Eco Cash system are 1.39

${ }^{2}$ The analysis of the results is undertaken per variable i.e. holding fixed the impact of the other variables and the base category. 
times likely to withdraw all their money from banks. The odds of LP for an individual whose dependents are older than 18 years of age is 0.9 times less than that of one whose dependents are younger. This can be supported by the realistically higher costs of catering for younger dependents. The CARDUSE variable measures whether individuals use alternative methods of transacting such as debit cards, credit cards and cheques while ATMACCESS shows individuals' access to ATMs. The results show that individuals are 0.31 and 0.58 times less likely to require holding all their money at once if they use alternative transaction methods and get easy access to ATMs respectively. The results for ATMACCESS are not statistically significant though. The odds of liquidity preference for respondents who have confidence in banks and those who reside in urban areas are 0.50 and 0.42 less than their opposites respectively.

With the estimation and results of the model complete, there is need to assess the robustness and fit of the methodology utilized. Tests for model fit, coefficient and residual diagnostics are carried out and presented.

Table 3: Expectation-Prediction Evaluation for Binary Specification

\begin{tabular}{|l|c|c|c|c|c|c|}
\hline \multicolumn{7}{|c|}{ Expectation-Prediction Evaluation for Binary Specification } \\
\hline & \multicolumn{7}{|c|}{ Success cutoff: C $=0.5$} \\
\cline { 2 - 7 } & SAVE & LP & Total & Dep=0 & Dep=1 & Total \\
\hline E(\# of Dep=0) & 130 & 57 & 187 & 111 & 76 & 187 \\
\hline E(\# of Dep=1) & 57 & 71 & 128 & 76 & 52 & 128 \\
\hline Total & 187 & 128 & 315 & 187 & 128 & 315 \\
\hline Correct & 130 & 71 & 201 & 111 & 52 & 163 \\
\hline \% Correct & 69.52 & 55.47 & 63.81 & 59.36 & 40.63 & 51.75 \\
\hline$\%$ Incorrect & 30.38 & 44.53 & 36.06 & 40.64 & 59.37 & 48.25 \\
\hline Total Gain* & 10.16 & 14.84 & 12.06 & & & \\
\hline Percent Gain** & 25.00 & 25.00 & 25.00 & & & \\
\hline *Change in "\% Correct" from default (constant probability) specification \\
\hline **Percent of incorrect (default) prediction corrected by equation \\
\hline
\end{tabular}

Table 3 shows evaluation of the model based on the predicted and estimated results. The test uses a 0.5 cut off point to assess the success of the model. For more stringent tests, lower cut off points can be used. The model permits the classification of individuals subject to the decision priory assigned to them. In the model, if the probability of the decision or event is greater than the 0.5 cut off threshold, then the event is assumed to have occurred. This is the 'Decision Rule'. The evaluation disaggregates the event into LP $>0.5$ and $\mathrm{SAVE}<=0.5$. Table 3 shows that the decision rule correctly classified $55.47 \%$ of the individuals where the predicted event (LP) occurred. This is known as the 'Sensitivity of Prediction'. It is the percentage of events correctly predicted or P(Correct|Event did occur). This was a $14.84 \%$ improvement in success rate from the Constant equation ${ }^{3}$. The decision rule also permits for the 'Specificity of Prediction' of $69.52 \%$ which was a $10.16 \%$ predictive improvement from the constant equation. It is the percentage of correctly predicted events that did not occur or P(Correct|Event did not occur). The model was correct 201 out of 315 times. The overall success rate, which is the model's Count R2 is $63.81 \%$. This is relatively high given the lower McFadden R2 of 0.2056454 . Conversely, the model was susceptible to error. The model had a false positive rate of $44.53 \%$. This was the rate at which the model predicted that the event occurred when in fact it did not. The false negative rate was $30.48 \%$. This was the rate at which the model predicted that the event did not occur when in fact it did.

Table 4: Wald's Coefficient Diagnostic Tests

\begin{tabular}{|c|c|c|c|}
\hline \multicolumn{5}{|c|}{ Wald's Test } \\
\hline Coefficient & $X^{2}$ value & df & Prob. \\
\hline$C(1)$ & 4.868 & 1 & 0.027 \\
\hline$C(2)$ & 1.804 & 1 & 0.179 \\
\hline$C(3)$ & 6.641 & 1 & 0.010 \\
\hline$C(4)$ & 0.001 & 1 & 0.922 \\
\hline$C(5)$ & 7.016 & 1 & 0.008 \\
\hline$C(6)$ & 1.760 & 1 & 0.185 \\
\hline
\end{tabular}

\footnotetext{
${ }^{3}$ The Constant equation (base equation) is the equation that uses the constant term. No regressor variables are present. It is utilized as a means of assessing the improvement induced in the model by additional variables.

${ }^{4}$ McFadden R2 = 1- (LLFur/LLFr). LLFur is the unrestricted log likelihood function in the model were all explanatory variables are included while LLFr is the restricted log likelihood of the constant model (Gujarati, 2004). They are equivalent to RSS and TSS in linear regression. 


\begin{tabular}{|c|c|c|c|}
\hline $\mathrm{C}(7)$ & 37.873 & 1 & 0.000 \\
\hline $\mathrm{C}(8)$ & 4.171 & 1 & 0.041 \\
\hline $\mathrm{C}(9)$ & 20.590 & 1 & 0.000 \\
\hline Model & 60.526 & 8 & 0.000 \\
\hline
\end{tabular}

The Wald coefficient test assesses the ability of the coefficients to explain the changes in the explanatory variables. The test can also be used to assess the joint effect of explanatory variables that are insignificant alone. The Wald test findings show that most of the coefficients are statistically significant with the exception of $C(2), C(4)$ and $C(6)$. Jointly, these coefficients still proved insignificant. Conversely, the model test $[60.526(0.000)]$ proved statistically significant with 8 degrees of freedom. This finding combined with the LR statistic of $87.51577(0.0000)$ means that the model coefficients are jointly suited to explain the regressand. The null hypothesis that the model coefficients fit the model will not be rejected therefore.

Table 5: The Hosmer-Lemeshow (H-L) Test

\begin{tabular}{|c|c|c|c|c|c|c|c|c|}
\hline \multicolumn{9}{|c|}{ Goodness-of-Fit Evaluation for Binary Specification } \\
\hline \multicolumn{9}{|c|}{ Andrews and Hosmer-Lemeshow Tests } \\
\hline & \multicolumn{3}{|c|}{ Quantile of Risk } & \multicolumn{2}{|c|}{ Dep $=0$} & Dep=1 & Total & $\mathrm{H}-\mathrm{L}$ \\
\hline & Low & High & Actual & Expect & Actual & Expect & Obs & Value \\
\hline 1 & 0.0257 & 0.0989 & 29 & 28.9178 & 2 & 2.08220 & 31 & 0.00348 \\
\hline 2 & 0.0993 & 0.1601 & 29 & 27.8148 & 3 & 4.18520 & 32 & 0.38614 \\
\hline 3 & 0.1604 & 0.2173 & 29 & 25.0247 & 2 & 5.97528 & 31 & 3.27620 \\
\hline 4 & 0.2202 & 0.2843 & 21 & 24.0819 & 11 & 7.91809 & 32 & 1.59396 \\
\hline 5 & 0.2861 & 0.3756 & 18 & 20.7215 & 13 & 10.2785 & 31 & 1.07800 \\
\hline 6 & 0.3771 & 0.4679 & 17 & 18.4652 & 15 & 13.5348 & 32 & 0.27489 \\
\hline 7 & 0.4685 & 0.5465 & 16 & 15.4382 & 15 & 15.5618 & 31 & 0.04072 \\
\hline 8 & 0.5642 & 0.6553 & 11 & 12.5495 & 21 & 19.4505 & 32 & 0.31477 \\
\hline 9 & 0.6622 & 0.7586 & 10 & 9.16402 & 21 & 21.8360 & 31 & 0.10827 \\
\hline 10 & 0.7611 & 0.9747 & 7 & 4.82230 & 25 & 27.1777 & 32 & 1.15792 \\
\hline & & Total & 187 & 187.000 & 128 & 128.000 & 315 & 8.23433 \\
\hline \multicolumn{3}{|c|}{ H-L Statistic } & 8.2343 & & \multicolumn{2}{|c|}{ Prob. Chi-Sq(8) } & 0.4109 & \\
\hline \multicolumn{3}{|c|}{ Andrews Statistic } & 12.5058 & & \multicolumn{2}{|c|}{ Prob. Chi-Sq(10) } & 0.2526 & \\
\hline
\end{tabular}

The $\mathrm{H}$-L test uses a Pearson $x^{2}$ statistic calculated from a $2 \cdot y$ table of estimated and observed expected frequencies. $y$ denotes the number of groups from the estimated probabilities (Peng and So, 2002). The null hypothesis of the H-L test is that the model does not fit the data. The null hypothesis would not have been rejected if the H-L test statistic was significant based on a chi-square value of less than 0.05 given 8 degrees of freedom. The results show that the $\mathrm{H}-\mathrm{L}$ statistic is $8.2343(0.4109)$. The null hypothesis is therefore rejected. The model therefore fits the data. The H-L statistic has the limitation that it becomes conservative and fails to reject the null hypothesis when given less than 6 groups. The logistic model utilized in the study overcomes this shortcoming.

\section{Conclusion and Policy recommendations}

The study focused on the major determinants of savings and liquidity in Zimbabwe. The study showed that significantly negative relationships exist between liquidity preference and confidence. The same relationship exists with the rate of debit card and cheque use as alternative transaction means. A significant positive relationship exists between liquidity preference and EcoCash use. These were considered as the major driving forces in influencing liquidity among households and deposits in banks.

Given the two primary findings, it is agreeable that improving confidence in the banking sector is the most difficult objective and can only be achieved in the long term after successes of other financial services sector policies have proved successful. To mitigate the liquidity challenges in the short run and solve both the need for consumption and investment funds, there is need for radical introduction of Points of Sale (POS) systems in retailing. It is clear that the majority of demand deposits are consumption driven. Relative to the region, Zimbabwe is pitifully lagging behind when it comes to plastic money transactions. As of 2013, about 10.8 million Kenyans used their Visa or Mastercards daily on the 18.796 POS stations available in the country (AFKInsider, 2013). Aggressive use of POS systems would undoubtedly boost the level of savings across the month period. Furthermore, POS transactions have the effect of increasing money 
supply via the money creation process.

For the sake of long term economic growth there is need for capital projects growth. In other words there is need for Zimbabwe to avail more funds for investment in large scale projects that improve infrastructure and promote FDI. Currently the availability of these funds is limited by the demand for consumption funds. EcoCash, although a working solution to current transaction problems, presents a long term hindrance to economic growth. Sustainable economic development will not be maintained by consumption. EcoCash is largely burdening the formal banking sector by finding loopholes in banking legislation and needs to be monitored. Its failure to provide the more critical services such as lending, investment, providing reserves to the Central Bank and being the backbone of the financial sector mean that its long term value is largely diminished. EcoCash is also a significant monopoly in mobile money transfer business. There is need to control its impact on money movement trends such that savings increase in formal banks. Services such as money transfers of notable magnitude should also be reserved for the financial services sector.

Based on the findings of this study, it is not suffice to elaborate to what extent these measures will perform. Further market and policy implementation strategy studies are needed.

\section{References}

AFKinsider., (2013) "Cash to Cashless: Visa, MasterCard Scramble For Africa." [Online]. Available: http://www.afkinsider.com Accessed: 24 November 2013.

Ahmad, K., and Mahmood, H., (2013) "Macroeconomic Determinants of National Savings Revisited: A small open economy of Pakistan." World Applied Sciences Journal 21(1).

Athukorala, P., and Sen, K., (2001) "The Determinants of Private Saving in India." Journal of Economic Development and Cultural Change.

Cadim de Cavarlho, F.J., (1998) "On Banks and Liquidity Preference." University of Rio de Janeiro. Brazil.

Callen, T., and Thimann, C., (1997) "Empirical Determinants of Household Savings: Evidence from OECD Countries." International Monetary Fund 97 (181).

Economist (2013) "Zimbabwe after hyperinflation: In dollars they trust." [Online] Available: http://www.economist.com

Engen, E.M., Gale, W.G and Scholz, J.K., (1996) "The Illusory effects of Savings Incentives on Savings." The Journal of Economic Perspectives.

Friedman, M., (1956) "The Quantity Theory of Money: A Restatement." University of Chicago Press.

Gujarati, D.N., (2004) "Basic Econometrics." McGraw-Hill International.

Gwenhamo, F., (2009) "Foreign Direct Investment in Zimbabwe: Role of Institutional Factors." University of Cape Town.

Kang, S., (2002) "The Estimation of Savings Function by Income Classes: A case of Korea. National Pension Research Institute.

Keynes, J. M., (1936) "The General Theory of Unemployment, Interest and Money." New York.

Loayza, N., Schmidt-Hebbel, K and Serven, L., (2000) "Savings in Developing Countries: An Overview. The World Bank Economic Review.

Lung, R.B., (2002) "Personal Savings as a function of Permanent Income." Virginia Polytechnic Institute and State University.

MacNealy, M.S., (1999) "Strategies of Empirical Research in Writing." Longman. New York.

Malinvaud, E., (1966) "Statistical Methods of Econometrics." Rand McNally:Chicago.

Mishkin, F.S., (2004) "Economics of Money, Banking and Financial Markets." Columbia University. Addison Wesley.

Modigliani, F., (1963) "The Life Cycle Hypothesis of savings, the demand for wealth and supply of capital." Bell and Howell Information and Learning Company (2000).

Nkwachuku, T.E and Egwaikhide, F.O., (2007) "An Error Correction Model of Determinants of Private Saving in Nigeria." University of Ibadan. Nigeria.

Peng, C.J., and So, T.H., (2002) "Logistic Regression Analysis and Reporting: A Primer." Department of Counseling and Education. Indiana Universisty.

RBZ Reserve Bank of Zimbabwe (2012) "2012 Mid Term Monetary Policy Statement." [Online] Available: http://www.rbz.gov.zw Accessed: 24 October 2013.

RBZ Reserve Bank of Zimbabwe (2012) "Monthly Economic Review: October 2012." [Online] Available: http://www.rbz.gov.zw Accessed: 26 December 2013.

RBZ Reserve Bank of Zimbabwe (2013) "Monthly Economic Review: October 2013." [Online] Available: http://www.rbz.gov.zw Accessed: 26 December 2013.

Rukuni, M., (2013) "Broadening and deepening rural financial services and land banking." [Online] Available: http://www.sokwanele.com

Snowdon, B and Vane, H.R., (2005) "Modern Macroeconomics." Edward Elgar, Cheltenhan UK.

Yilmazer, T., (2009) "The Profile and Determinants of Household Saving." University of Missouri. 